\title{
Aged mice display altered numbers and phenotype of basophils, and bone marrow- derived basophil activation, with a limited role for aging-associated microbiota
}

Adriaan A. van Beek ${ }^{1,2,3^{*}}$, Floris Fransen ${ }^{2,4}$, Ben Meijer ${ }^{1}$, Paul de Vos $^{2,4}$, Edward F. Knol ${ }^{5,6}$ and Huub F. J. Savelkoul ${ }^{1}$

\begin{abstract}
Background: The influence of age on basophils is poorly understood, as well as the effect of aging-associated microbiota on basophils. Therefore, we studied the influence of aging and aging-associated microbiota on basophil frequency and phenotype, and differentiation from basophil precursors.

Results: Basophils became more abundant in bone marrow (BM) and spleens of 19-month-old mice compared with 4month-old mice. Aged basophils tended to express less CD200R3 and more CD123, both in BM and spleen. Differences in microbiota composition with aging were confirmed by $16 \mathrm{~S}$ sequencing. Microbiota transfers from young and old mice to germ-free recipients revealed that CD11b tended to be lowered on splenic basophils by agingassociated microbiota. Furthermore, abundance of Alistipes, Oscillibacter, Bacteroidetes RC9 gut group, and S247 family positively correlated and CD123 expression, whereas Akkermansia abundance negatively correlated with basophils numbers.

Subsequently, we purified FcERla ${ }^{+} \mathrm{CD} 11 \mathrm{C}^{-} \mathrm{CD} 117^{-} \mathrm{BM}$-derived basophils and found that those from aged mice expressed lower levels of CD11b upon stimulation. Higher frequencies of $\mathrm{IL}-4^{+}$basophils were generated from basophil precursors of aged mice, which could be reproduced in basophils derived from germ-free recipients of aging-associated microbiota.
\end{abstract}

Conclusions: Collectively, these results show the influence of aging on basophils. Furthermore, this study shows that aging-associated microbiota altered activation of BM-derived basophils in a similar fashion as observed in BM-derived basophils from aged mice.

Keywords: Aging, Basophils, Immunity, Microbiota, Bone marrow, Spleen

\section{Background}

The human adult gut contains about $10^{13}-10^{14}$ bacteria $[1,2]$, which is comparable to the number of human cells in the total body of a 30-year-old adult [3]. These commensal gut microbiota modulate the immune system [4] and contribute to immune homeostasis in the mucosal immune system [5]. Gut microbiota play an important modulatory role beyond mucosal immunity, for instance by changing the stem cell niche in the bone

\footnotetext{
* Correspondence: a.vanbeek@erasmusmc.nl

${ }^{1}$ Cell Biology and Immunology Group, Wageningen University, Wageningen, the Netherlands

${ }^{2}$ Top Institute Food and Nutrition, Wageningen, the Netherlands

Full list of author information is available at the end of the article
}

marrow (BM) [6]. Furthermore, absence of microbe-derived peptidoglycan in the circulation impairs the killing by BM neutrophils of Salmonella pneumoniae and Staphylococcus aureus [7]. In addition, in the absence of microbiota, CD123 (IL-3R $\alpha$ ) expression on basophil precursors was upregulated, thereby enhancing their responsiveness to interleukin (IL) 3 [8].

During aging the immune system develops several defects and undergoes various changes in differentiation, distribution, and activation [9]. Anti-parasitic immune responses in aged mice are impaired [10], which may indicate age-related changes in basophil function [11]. With aging, gut microbiota composition changes [12].

(c) The Author(s). 2018 Open Access This article is distributed under the terms of the Creative Commons Attribution 4.0 International License (http://creativecommons.org/licenses/by/4.0/), which permits unrestricted use, distribution, and 
Basophil hematopoiesis and function are regulated by gut microbiota. Absence of gut microbiota lead to increased basophil frequencies and enhanced $\mathrm{T}$ helper (Th) 2 immune responses [8]. In addition, basophils express Toll-like receptor (TLR) 2 and TLR4, and respond to microbial ligands like peptidoglycan [13] and lipopolysaccharide (LPS) [14]. Histamine release and sensitivity of basophils from elderly were reported to be increased upon anti-immunoglobulin (Ig) E stimulation [15], but in a different study, no age-related difference was found in histamine release of human blood basophils upon anti-IgE or anti-IgG4 stimulation [16]. Basophil counts were not associated with frailty or mortality in elderly women $[17,18]$. Basophil frequencies and absolute numbers decreased in blood from healthy elderly volunteers and patients suffering from Alzheimer's disease $[19,20]$. It is, however, largely unknown what effect age has on basophil differentiation and function.

Basophils are granulocytes which are involved in mounting and perpetuating Th2-mediated responses [21]. Basophils are an important source of IL-4 and IL-13, which direct the immune response towards Th2 type responses [22]. After IgD crosslinking, basophils produced IL-1, IL-4 and B cell activating factor (BAFF), supporting B cell functions [23]. Basophils are the major source of IL-4 after Streptococcus pneumoniae infection, contributing to humoral memory immune responses [24]. In addition, the basophil is crucial in the pathophysiology of systemic lupus erythematosus $[25,26]$, and its counts are a marker for disease activity [27]. Recently, basophil infiltration into tumors after depletion of regulatory $\mathrm{T}$ cells was implicated in tumor rejection via $\mathrm{C}$-C motif chemokine ligand (CCL) 3- and CCL4-mediated recruitment of $\mathrm{CD}^{+} \mathrm{T}$ cells to tumors [28], indicating a role beyond classical Th2 responses.

Basophil differentiation and functions are dependent on IL-3 or thymic stromal lymphopoietin (TSLP) [29]. Basophils can be activated in an IgE-dependent and IgE-independent manner. Regarding IgE-dependent activation, FceRI $\alpha$ crosslinking by complexes of IgE and antigen activates basophils, resulting in IL-4 and IL-13 production [30]. Basophils express IL-18R and IL-33R (ST2), and upon stimulation with IL-18 and IL-33, basophils produce IL-4, IL-6, IL-13, granulocyte-macrophage colony stimulating factor (GM-CSF), and several chemokines [31]. This effect is further enhanced in the presence of IL-3 [32]. CD200R3-mediated activation of basophils leads to IL-4 production in vitro, and to anaphylaxis in vivo [33].

Here we studied the influence of the aging-associated microbiota on basophil frequency and phenotype, and differentiation from precursors of basophils. We compared basophils from young germ-free recipients of microbiota of 4-month-old to young germ-free recipients of microbiota of 18-month-old mice. In addition, we studied changes in frequency and phenotype of basophils in BM and spleen, correlation between microbial genera and basophils, and changes in differentiation from precursors of basophils during aging by comparing 4-month-old and 18-month-old mice.

\section{Results \\ Basophils become more abundant during aging and display a changed phenotype}

To identify the effect of age on basophil frequencies and phenotype, we analyzed frequencies of lineage (Lin) ${ }^{-} \mathrm{CD} 117^{-}{ }^{-} \mathrm{Fc} R \mathrm{RI}^{+} \mathrm{CD} 200 \mathrm{R} 3^{+}$basophils in mouse BM (Fig. 1a) and spleen (Fig. 1d), as well as absolute numbers. By comparing young and old mice, we found that the frequencies of basophils in the $\mathrm{BM}$ were similar (Fig. 1c), but were increased in the spleen of aged mice $(p=0.03$; Fig. 1f), whereas absolute numbers were increased in BM $(p=0.02)$ and spleen $(p=0.06$; Fig. 1c, f). The phenotype of basophils changed in both BM and spleen. CD200R3 expression tended to decrease on basophils in the BM $(p<0.08$; Fig. 1b, c) and was decreased in the spleen of aged mice ( $p=0.04$; Fig. 1e, f), but CD123 expression was increased in aged basophils in the $B M(p=0.04)$ and tended to be increased in the spleen $(p=0.07)$. No age-related changes in FceRI $\alpha$, TSLPR, CD11b, and IL-33R (Fig. 1c, f) were observed.

\section{Microbiota composition changes with age and after microbiota transfer of young and aged mice}

Because it has been reported that basophils are regulated by gut microbiota [8], we determined differences in microbial genera (L6) between young and aged mice by $16 \mathrm{~S}$ sequencing. Alistipes, Bacteroidetes RC9 gut group, S24-7 family (L5), and Oscillibacter were significantly more abundant in aged mice compared with young mice, whereas Lactobacillus was significantly less abundant (Fig. 2a).

Next, we questioned whether the differences in basophils with aging are caused by gut microbiota. To this end, microbiota obtained from fecal samples of 4-month-old or 18-month-old mice were transferred to 3-month-old germ-free mice. After 1 week and after 4 weeks, we determined differences in microbial genera between germ-free recipients of young or old microbiota. After 1 week, the abundance of Alistipes, Ruminococcus, and Akkermansia was significantly decreased in recipients of old microbiota, compared with young microbiota, whereas Lactobacillus abundance tended to increase (Fig. 2b). After 4 weeks, the abundance of Prevotellaceae unclassified was significantly lower in recipients of old microbiota, compared 


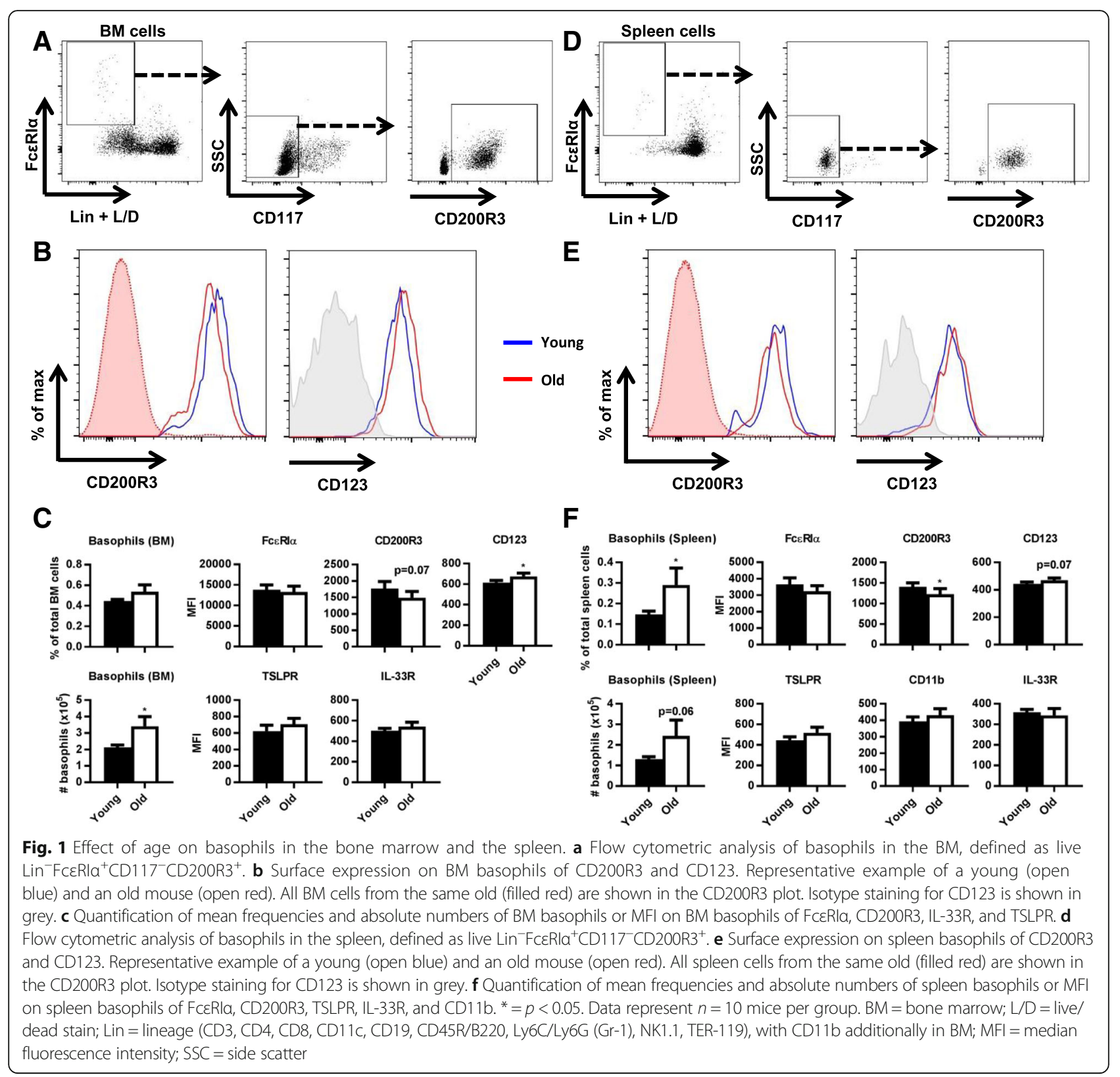

with young microbiota, and the abundance of Desulfovibrio was significantly higher (Fig. 2c).

\section{No difference in basophil frequencies and phenotype} after microbiota transfer of young and aged mice

After microbiota transfers, we found no significant effects on frequencies, numbers, nor on phenotype of basophils (Fig. 3a, b). Both BM and spleen had similar basophil frequencies and numbers in the young or old microbiota recipients (Fig. 3a, b). In addition, no difference in FceRI $\alpha$, TSLPR, CD200R3, IL-33R, and CD123 was observed between young and aged recipient-mice. The only difference we observed was in splenic basophils that tended to express less CD11b in recipients of 18 -month-old microbiota $(p<0.06$; Fig. 3b). Because we did not observe changes in basophil distribution and phenotype after microbiota transfers, we checked whether the distribution and phenotype differed between conventional and germfree mice. We found no differences between germ-free and conventional mice in terms of frequencies and absolute numbers of basophils. We confirmed that the absence of microbiota changed the phenotype of basophils. In particular, FceRI $\alpha$ expression was more than 2 -fold decreased on BM and splenic basophils from germ-free mice, in comparison with conventional mice 


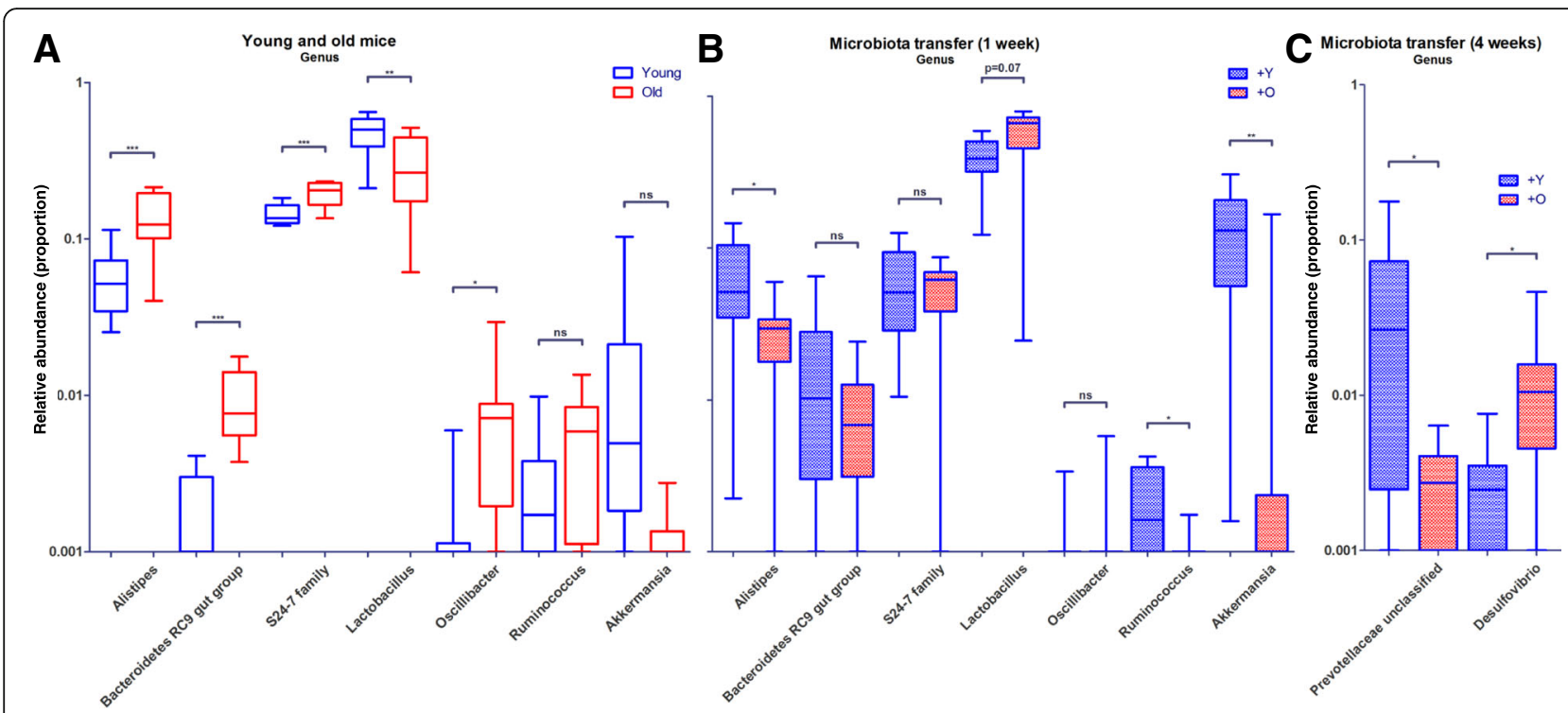

Fig. 2 Effect of age and age-related microbiota on microbiota composition. a Bacterial genera that were significantly different in abundance in young or old mice. $\mathbf{b}$-c Bacterial genera that were significantly different between germ-free recipients of young or old microbiota, after 1 week or after 4 weeks of transfer. $+\mathrm{O}=$ microbiota derived from old mouse; $+\mathrm{Y}=$ microbiota derived from young mouse. ${ }^{*}=p<0.05 ;{ }^{* *}=p<0.01 ;{ }^{* * *}=p<0.001$

(Fig. 3c, d). CD200R3 and IL-33R expression on splenic basophils was also decreased in germ-free mice (Fig. 3d).

\section{Association between basophil numbers or basophil phenotype, and abundance of microbial genera}

Based on the microbial genera that were significantly different with aging or after microbiota transfers (Fig. 2), we subsequently investigated the association between gut microbiota and basophil frequencies and phenotype. We found that abundance of Alistipes, Oscillibacter, Bacteroidetes RC9 gut group, and S24-7 family positively correlated with CD123 expression in BM and/or spleen (Fig. 4a, b, c, d). The abundance of Desulfovibrio positively correlated with IL-33R expression on basophils in BM and spleen (Fig. 4e). In addition, we found that abundance of Lactobacillus positively correlated with CD11b expression by splenic basophils (Fig. 4f). Finally, Akkermansia abundance negatively correlated with basophil numbers in BM and showed a similar tendency with splenic basophil numbers (Fig. 4g).

In vitro function of bone marrow-derived basophils from old mice is impaired in part due to microbiota

Although frequency and the majority of the phenotypical markers were not influenced by the age of the microbiota, we wished to exclude that other differential functional parameters of the basophils were still intact. To this end we differentiated basophils in vitro from bone marrow and subsequently tested the functional response of purified basophils on several stimuli.
Differentiation adequacy into $\mathrm{FceRI \alpha}^{+} \mathrm{CD} 117^{-}$basophils (and CD200R3 ${ }^{+}$basophils) or FceRIa ${ }^{+} \mathrm{CD} 117^{+}$mast cells was determined by flow cytometry after 4,7 , and 10 days of culture (Fig. 5a). No differences in expansion of the whole culture, or differentiation were observed among the experimental groups (Table 1; Fig. 5b). About $98 \%$ of basophils were CD200R ${ }^{+}$after 10 days of culture (data not shown).

After 10 days of culturing BM cells with IL-3, we isolated the basophils (Fig. 6a). Purified BM-derived basophils (BMB) were overnight cultured under five different conditions: medium, IL-18 + IL-33, TSLP, IgE, or CD200R3. These conditions mimic different routes of activation of basophils [21]. The five different conditions resulted in distinct basophil phenotypes. IL-18 + IL-33 and CD200R3 were most potent in the induction of IL-4 and IL-13 by the basophils (Fig. 6b). For Ki-67, IL-4, and IL-13, but not CD11b expression, we observed a stimulus-dependent effect (Fig. 6c).

$\mathrm{CD} 11 \mathrm{~b}$ expression was decreased in BMB derived from 4-month-old mice compared with those from 18-monthold mice $(p<0.001$; Fig. $6 c)$. This was not microbiotadependent, because CD11b was not altered in BMB derived from germ-free recipients of old microbiota compared with recipients of young microbiota (Fig. 6d). We originally planned to use $\mathrm{Ki}-67$ as a measure of proliferation [34], but this was not applicable as most BMB were Ki-67 ${ }^{+}$(Fig. 6b). We therefore focused on a distinct cell population with high expression of $\mathrm{Ki}-67\left(\mathrm{Ki}-67^{++}\right)$as measure for proliferative activity. With aging, the frequency of $\mathrm{Ki}-67^{++} \mathrm{BMB}$ consistently increased under all tested conditions $(p<0.001$; Fig. $6 \mathrm{c})$. The frequency of 


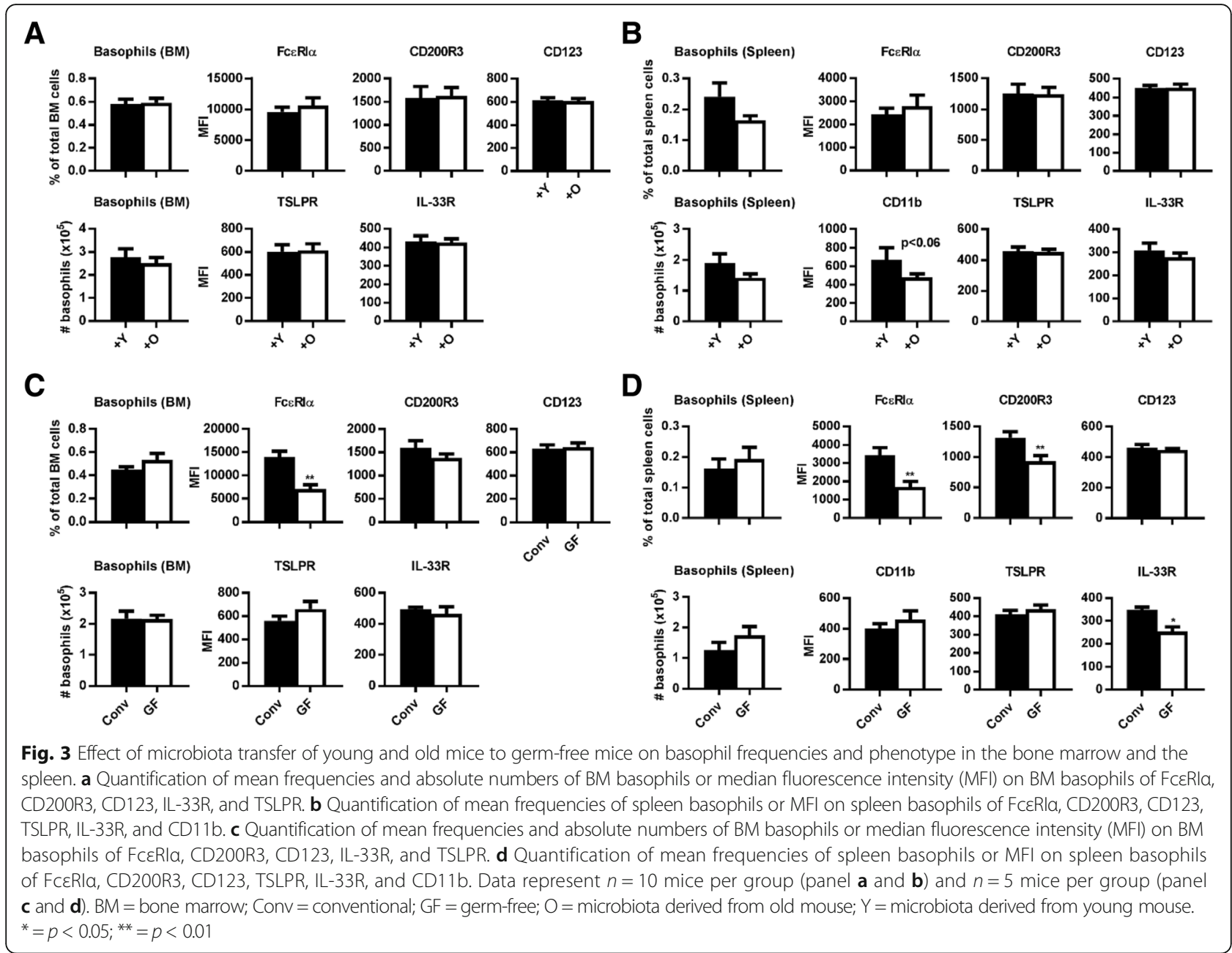

IL- $4^{+}$cells increased in old BMB $(p<0.05$; Fig. $6 \mathrm{c})$. This seemed to be influenced by microbiota, because similar differences were observed in BMB from recipients of old microbiota $(p<0.01$; Fig. $6 \mathrm{~d})$. The $\mathrm{IL}-13^{+}$frequency did not change with age (Fig. 6c), but did increase upon transfer of old versus young microbiota $(p<0.01$; Fig. $6 \mathrm{~d})$. We compared the five culture conditions in aging, and after transfer of microbiota, but found the most pronounced effects in cultures stimulated with CD200R3, IL-18 + IL-33, and TSLP (Fig. 6c-d).

\section{Discussion}

In this study, we found that basophil frequencies, numbers, and phenotype in the spleen change in mice during aging. Less effects on phenotype were found in the BM, although absolute numbers of basophils increased. This however should not be interpreted as a suggestion that no aging effects in the BM exist, as significant effects of age were found on the in vitro activation of basophils differentiated from precursors in the BM. Partly these in vitro effects were caused by the aging microbiota, as age-dependent changes in the activation of BM-derived basophil were also observed in young germ-free recipients of microbiota of 18-month-old mice. Fecal microbiota analysis showed that the microbiota composition significantly changed with age, and after microbiota transfers. Several microbial genera were correlated with basophil frequencies and phenotype.

Our report confirms age-related effects on basophils, showing for the first time that basophil phenotype changes. Intriguingly, CD123 expression by basophils from old mice consistently tended to increase. CD123 is crucial for IL-3 signaling and basophil hematopoiesis [29], and might explain the increased basophil numbers. IL-3 is, in higher amounts, also able to induce IL-4 production in basophils via the IL-3 receptor [35]. Aged basophils showed a tendency to lower expression of CD200R3, which inhibits FceRI $\alpha$-mediated activation of basophils [36]. CD200R3 also activates basophils to produce IL-4 and to degranulate [33]. Lower CD200R3 expression by basophils from aged mice (versus basophils 

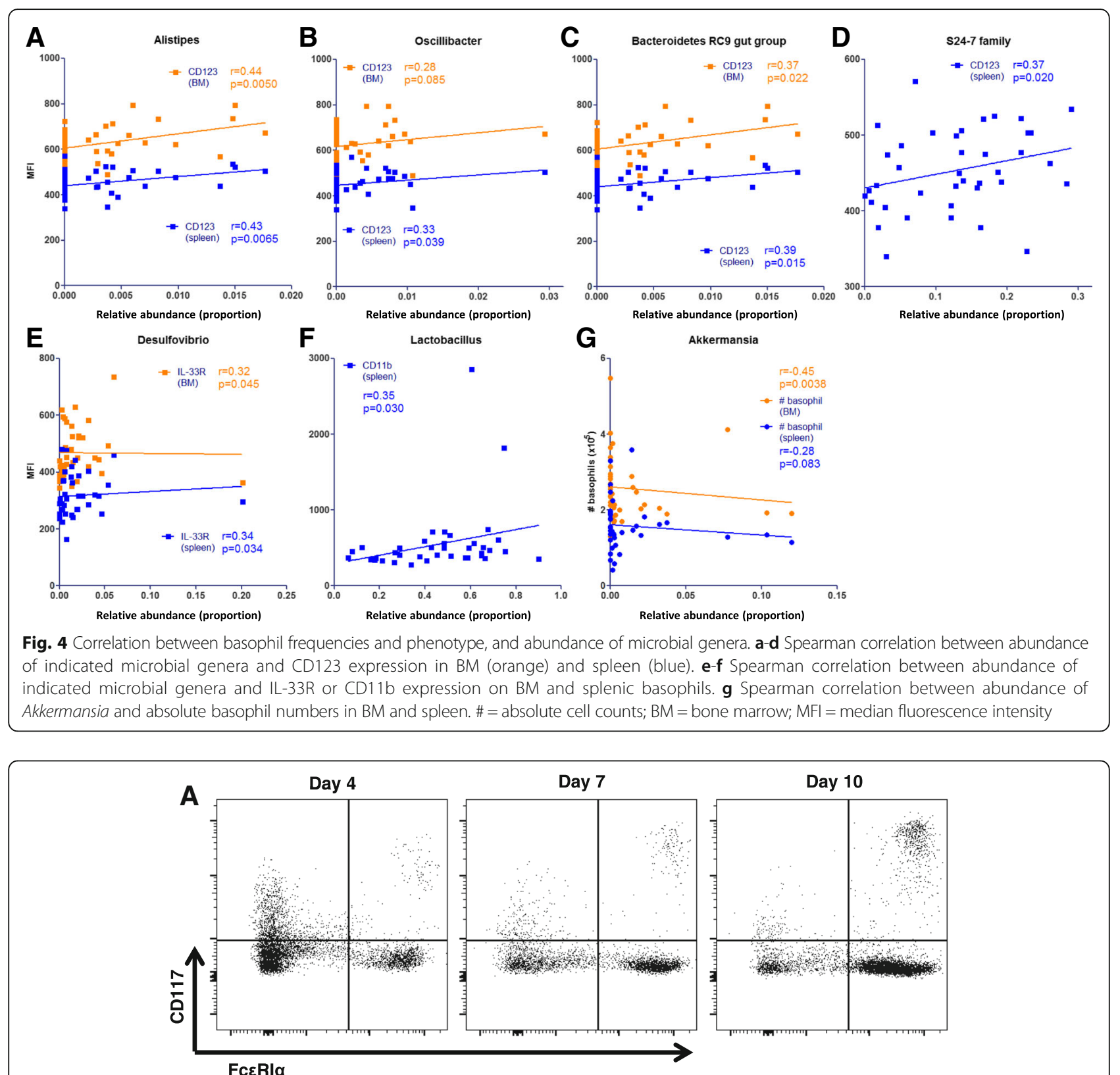

B
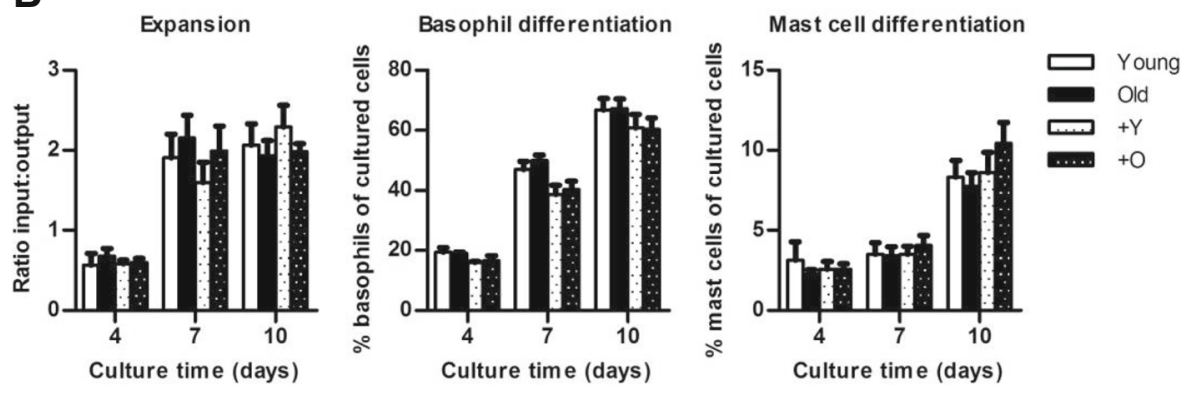

Fig. 5 Effect of age and age-related microbiota on IL-3 BM cultures. a Representative gating of IL-3-driven BM culture, in which all live cells were gated for CD117 and FceRla. Basophils were defined as FcERla ${ }^{+} \mathrm{CD} 117^{-}$and mast cells as FcERla ${ }^{+} \mathrm{CD} 117^{+}$. b Effect of age and microbiota on BM culture expansion and basophil and mast cell differentiation. Data represent $n=4$ cultures per group for day 4 and $n=5$ cultures per group for day 7 and 10 (with each culture derived from a different mouse). $\mathrm{O}=$ microbiota derived from old mouse; $\mathrm{Y}=$ microbiota derived from young mouse 


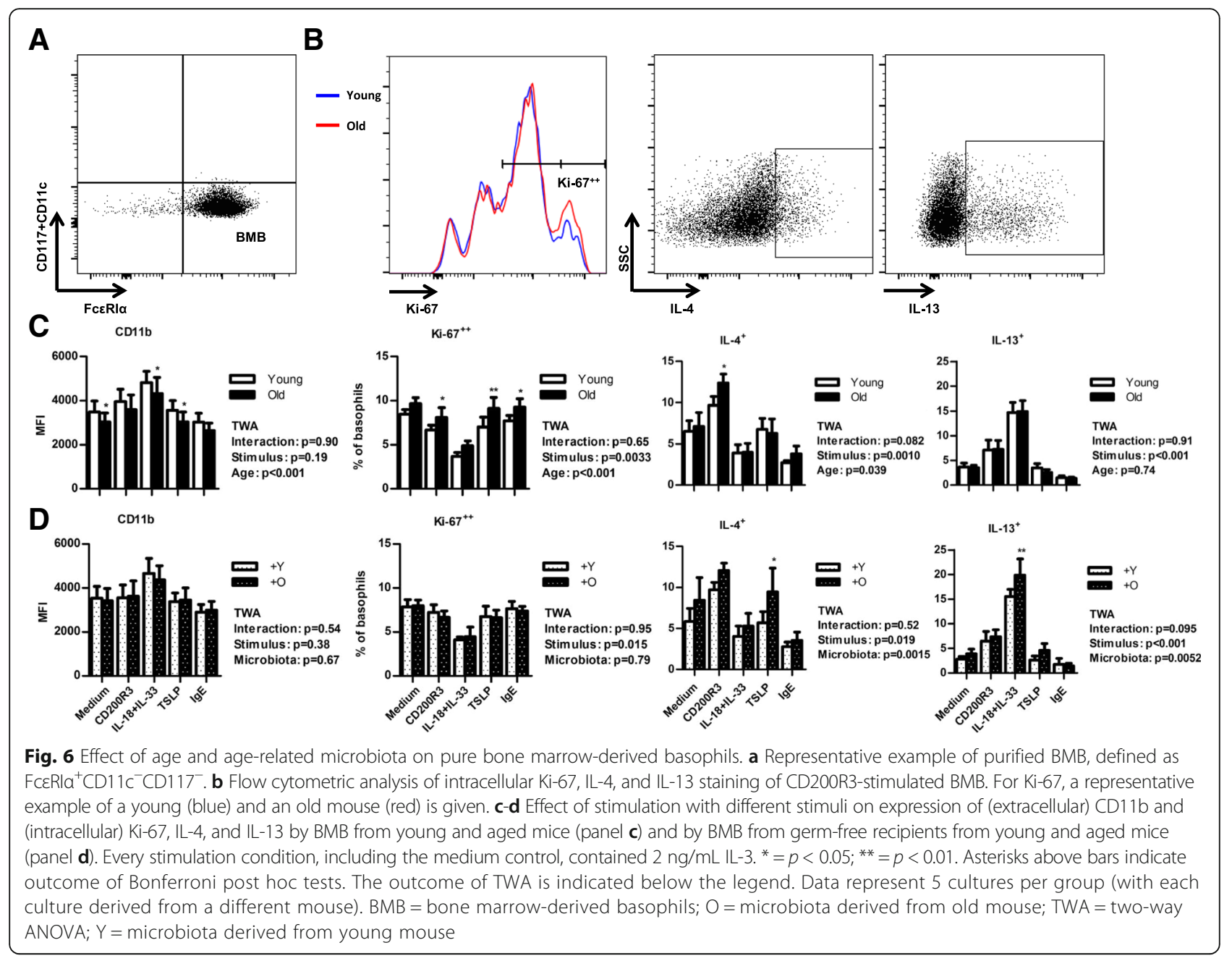

from young mice) might indicate that aged basophils are less readily activated [33]. Together, these age-related changes might indicate an increased sensitivity to IL-3, and at the same time an altered threshold for activation. Thus, we were able to show differences in BM and spleen basophils with age.

Recently, we have shown a correlation between B cell precursors and abundance of specific microbial genera [37]. Similarly, in this study, we found an association between specific microbial genera and basophil frequencies and phenotype (both in BM and spleen). Most strikingly, the abundance of Alistipes, Oscillibacter, Bacteroidetes RC9 gut group, and S24-7 family positively correlated with CD123 expression in BM and spleen. As indicated above, CD123 is crucial for basophil hematopoiesis and function. Transfer of specific microbiota into germ-free recipient mice would further support the association of microbial genera with basophil frequencies and phenotype we found in this study. Because basophils express TLR2 and TLR4 [13], it would be of high interest to determine expression of these receptors as well as responsiveness to their ligands in the context of aging.

To gain insight into the effect of aging on the precursors of basophils, we used IL-3-dependent BM cultures as a proxy (Fig. 5). First, we improved the method to generate basophils by at least 70 -fold compared with a recent, detailed protocol [31]. Yoshimoto et al (2012) reported using femurs and tibias of ten 9- to 12-monthold Balb/c male mice. A conservative estimation of the starting number of BM cells in their cultures is $4 \times 10^{8}$, which resulted in $20-40 \times 10^{6}$ cultured cells (culture efficiency $\leq 10 \%)$. After purification, $1-4 \times 10^{6}$ basophils were collected (purification efficiency $\leq 10 \%$ ). Under the best conditions, the mentioned protocol ends with a $1 \%$ yield. In our hands, the culture efficiency of the improved $\mathrm{BMB}$ generation protocol was higher than previously reported, with each $10^{6} \mathrm{BM}$ cells generating on average $2 \times 10^{6}$ cultured cells. Taking into account the withdrawal of cells for direct assessment three times during the culture, our culture efficiency was a bit 
Table 1 Average input, output, yield, and purity of basophils from IL-3 BMB cultures

\begin{tabular}{lllll}
\hline Group & $\begin{array}{l}\text { Input BM } \\
\text { cells } \times 10^{6}\end{array}$ & $\begin{array}{l}\text { Output cultured } \\
\text { cells } \times 10^{6}\end{array}$ & $\begin{array}{l}\text { Yield pure } \\
\text { basophils } \times 10^{6}\end{array}$ & Purity \% \\
\hline Young & $5.6(0.4)$ & $11.6(1.9)$ & $4.5(1.1)$ & $97(1)$ \\
Old & $6.0(0.0)$ & $11.6(1.1)$ & $3.2(1.3)$ & $97(1)$ \\
$+Y$ & $6.0(0.0)$ & $13.7(1.6)$ & $3.7(1.2)$ & $97(1)$ \\
$+O$ & $5.6(0.4)$ & $11.0(0.7)$ & $3.4(1.0)$ & $95(2)$ \\
\hline
\end{tabular}

Data represent 5 cultures per group (with each culture derived from a different mouse). Standard error of the mean between brackets $B M$ bone marrow, $B M B$ bone marrow-derived basophils, $+O$, microbiota derived from old mouse, $+Y$ microbiota derived from young mouse

higher than $200 \%$. Our purification method, which includes dendritic cell removal, resulted in higher numbers of pure basophils: we isolated on average $6.9 \times 10^{6}$ pure basophils per $20 \times 10^{6}$ cultured cells (35\% purification efficiency). Regardless different origins of BM (Table 1), our protocol ends with an average yield of $70 \%$. The vast difference between the yields are most likely explained by the cell density at the start of the culture. Other differences that might cause improved yield are mouse strain, fresh versus frozen $\mathrm{BM}$, and the purification method. Thus, using our robust method, we were able to assess basophil function by using a few million BM cells as input. It is important to underline the importance of excluding the adherent cells during the culture and the targeted depletion of $\mathrm{CD}_{11 \mathrm{c}^{+}}$dendritic cells during the isolation of BMB. This enables to specifically look at BMB responses, without bystander effects of stromal cells or dendritic cells.

We identified additional differences between young and aged BMB (Fig. 6). CD11b expression was decreased, whereas IL- $4^{+}$(but not IL-13 ${ }^{+}$) frequencies were increased upon activation in BMB from aged mice. IL- $4^{+}$ basophil frequencies were particularly increased after CD200R3 stimulation, in line with previous studies [33]. $\mathrm{BMB}$ derived from germ-free recipients receiving microbiota of aged mice (versus microbiota of young mice) also showed increased IL- $4^{+}$basophil frequencies. Thus, we found that microbiota from aged mice influence basophil precursors and subsequent in vitro activation.

The functional implications of these findings remain to be elucidated. It is conceivable that basophils may differ in their functional response in vivo, because Hill et al (2012) showed that antibiotics under steady state conditions in vivo did not alter basophil frequencies in lymph nodes. Basophil frequencies, however, were increased after papain treatment in antibiotic-treated mice (compared with control mice) [8]. Allergic challenges or helminth infections in young versus aged mice would give insight in the functional consequences in vivo of the observed changes between young and aged basophils, and after microbiota transfers of young and aged mice.

Our study has a number of limitations: 1) Due to the relatively small populations of basophils and the required numbers of aged and germ-free mice, we were not able to sort basophils directly from spleen or bone marrow to evaluate in vitro basophil function. 2) We could not study alterations in in vivo production of e.g. IL-4 by basophils with aging, as could be done by using aged or germ-free IL-4-eGFP reporter mice. 3) We used total aging-associated microbiota, rather than selected microbial strains that were altered upon aging and correlated with basophil phenotype or numbers.

\section{Conclusions}

Our study shows that aged mice display increased basophil numbers and altered phenotype, which seems independent of aging-associated microbiota. In vitro activation of BM-derived basophils is impaired with aging, which in part is explained by aging-associated microbiota. Further functional in vivo studies are warranted to investigate the consequences of our findings for Th2-mediated immune responses in aging.

\section{Methods}

\section{Mice}

Young and old wild-type C57Bl/6 mice were purchased from Harlan (Horst, The Netherlands). Germ-free C57Bl/6 mice were generated at the Central Animal Laboratory of the Radboud University Medical Center (Nijmegen, The Netherlands). Mice were kept in individually ventilated cages or sterile incubators, and were specific pathogen free (SPF). All mice had free access to feed (ssniff, rat/mouse maintenance V153X R/M-H) and water. All groups consisted of $n=10$ mice, unless otherwise mentioned. We have used mice as an animal model, because most tools are available for this animal model. We have used 19-20-months-old mice as aged, because many age-related changes have been reported to occur already at that age, and because tumor incidence increases after 20 months [38, 39].

\section{Microbiota transfers}

Feces from 4-month-old and 18-month-old female mice were freshly collected. Part of the feces was stored for microbial analysis, the remaining part was mixed with PBS. Three-month-old germ-free mice were administered $200 \mu \mathrm{L}$ of $100 \mathrm{mg} / \mathrm{mL}$ fecal solution by intragastric gavage $(20 \mathrm{mg} /$ mouse). These mice were then housed in IVC for another month.

\section{Organ collection and cell suspensions}

At 4-5 months or 19-20 months of age, mice were anesthetized with isoflurane, bled, and sacrificed by 
cervical dislocation. Serum was collected by spinning the clotted blood, and was stored at $-80{ }^{\circ} \mathrm{C}$ until further analysis. Mice were inspected for visible tumors, which lead to the exclusion of one aged mice. Femurs and spleen of each mouse were isolated. Single-cell suspensions of BM were obtained by flushing the femurs, whereas the spleen was cut in pieces. Cells were then passed through a cell strainer. Part of the BM cells were frozen for later use in vitro.

\section{Flow cytometry}

Flow cytometry was performed using standard procedures. After staining for surface markers, cells were incubated with live/dead eFluor506 or eFluor520 stain (Ebioscience). Cells were then fixed using the FoxP3/ Transcription Factor Staining Buffer kit (Ebioscience), with the exception of the Golgi-Stop-treated cells. They were processed using the Intracellular Fixation and Permeabilization kit (Ebioscience) to preserve intracellular cytokines. Used antibodies are listed in Table 2. Flow cytometric measurements were acquired by a FACSCanto II flow cytometry (BD Biosciences, Erembodegem,

Table 2 Used antibodies for flow cytometry and purification

\begin{tabular}{|c|c|c|c|}
\hline Target & Format & Clone & Company \\
\hline$\overline{\mathrm{CD}} 3 \mathrm{e}$ & FITC & $145-2$ C11 & $\mathrm{BD}$ \\
\hline CD4 & FITC & H129.19 & $\mathrm{BD}$ \\
\hline CD8a & FITC & $53-6.7$ & $\mathrm{BD}$ \\
\hline CD11b & BV421/FITC & $\mathrm{M} 1 / 70$ & $\mathrm{BD}$ \\
\hline CD11c & Biotin/FITC & HL3 & $\mathrm{BD}$ \\
\hline CD16/32 & FITC/Purified & $2.4 \mathrm{G} 2$ & $\mathrm{BD}$ \\
\hline CD19 & FITC & 1D3 & Ebioscience \\
\hline CD45R/B220 & FITC & RA3-6B2 & $\mathrm{BD}$ \\
\hline CD62L & APC-Cy7 & MEL-14 & $\mathrm{BD}$ \\
\hline CD117 & $\begin{array}{l}\text { Biotin } \\
\text { BV421 } \\
\text { BV510 }\end{array}$ & $\begin{array}{l}\text { 2B8 } \\
\text { 2B8 } \\
\text { ACK2 }\end{array}$ & $\begin{array}{l}\text { BD } \\
\text { BioLegend } \\
\text { BioLegend }\end{array}$ \\
\hline CD123 & $\begin{array}{l}\text { Biotin } \\
\text { PE }\end{array}$ & $\begin{array}{l}5 B 11 \\
5 B 11\end{array}$ & $\begin{array}{l}\text { BD } \\
\text { Ebioscience }\end{array}$ \\
\hline CD200R3 & APC & Ba13 & BioLegend \\
\hline FceRla & Biotin/PE-Cy7 & MAR-1 & Ebioscience \\
\hline IL-4 & APC & $11 \mathrm{~B} 11$ & Ebioscience \\
\hline IL-13 & PE-Cy7 & eBio13A & Ebioscience \\
\hline IL-33R/ST2 & PerCP-eFluor710 & RMST2-2 & Ebioscience \\
\hline $\mathrm{Ki}-67$ & FITC & SolA15 & Ebioscience \\
\hline $\begin{array}{l}\text { Ly6C/Ly6G } \\
(\mathrm{Gr} 1)\end{array}$ & FITC & RB6-8C5 & $\mathrm{BD}$ \\
\hline NK1.1 & FITC & PK136 & Ebioscience \\
\hline TER-119 & FITC & TER-119 & $\mathrm{BD}$ \\
\hline TSLPR & PE & & $R \& D$ \\
\hline Streptavidin & APC-eFluor780 & & Ebioscience \\
\hline
\end{tabular}

Belgium). FlowJo software vX.07 (Tree Star, San Carlos, USA) was used for data analysis.

\section{$16 \mathrm{~S}$ sequencing}

At sacrifice of all mice, fecal pellets from colon were sampled, snap frozen in liquid nitrogen, and stored at $-80{ }^{\circ} \mathrm{C}$. These samples were used for $16 \mathrm{~S}$ rRNA gene analysis for microbiota profiling, as further described in Fransen et al. 2017 [40]. Microbial genus (L6) data were used throughout this manuscript, unless otherwise indicated.

\section{Basophil generation and stimulation in vitro}

$\mathrm{BM}$ cells were thawed, checked for viability by trypan blue, and counted. BM cells were cultured, using an optimized method that was adapted from a previously published protocol [31]. About $3.3 \times 10^{5}$ viable BM cells per $\mathrm{mL}$ culture medium were plated in 6-wells plates. Culture medium consisted of RPMI-1640 medium (Gibco, Breda, The Netherlands), 10\% fetal calf serum (Gibco), $100 \mu \mathrm{g} / \mathrm{mL}$ Normocin (Invivogen, San Diego, USA), $2 \mathrm{ng} / \mathrm{mL}$ rmIL-3 (Sanquin, Amsterdam, The Netherlands), and $50 \mu \mathrm{M} \beta$-mercaptoethanol (SigmaAldrich, Zwijndrecht, The Netherlands). Cells were cultured for 10 days. Every 3-4 days, non-adherent cells were collected, counted, and re-plated. About $10^{5}$ cells were used for flow cytometry to measure proliferation and differentiation in the cultures (see Table 1 for antibodies). Expansion of each culture was calculated by dividing the cell count by the input. After 10 days, cells were incubated with purified anti-CD16/32 and subsequently with biotinylated CD11c and CD117 (all BD Biosciences, San Jose, USA). Cells were then incubated with streptavidin-coated IMag beads (BD) and processed with the IMagnet (BD). The negative fraction was incubated with biotinylated FceRI $\alpha$ and subsequently with streptavidin-coated IMag beads and processed with the IMagnet. The positive fraction (containing $\mathrm{CD} 11 \mathrm{c}^{-} \mathrm{CD} 117^{-}{ }^{\mathrm{F}} \mathrm{e} R \mathrm{RI \alpha}{ }^{+}$cells) were defined as BM-derived basophils, and purity typically exceeded 95\% (average $>96 \%$ ). Pure BMB were resuspended to $5 \times$ $10^{5} / \mathrm{mL}$ and stimulated for $15 \mathrm{~h}$ with culture medium (including IL-3) alone, $1 \mu \mathrm{g} / \mathrm{mL}$ rmTSLP (Ebioscience, San Diego, USA), $5 \mu \mathrm{g} / \mathrm{mL}$ CD200R3 (BioLegend, San Diego, USA), $10 \mu \mathrm{g} / \mathrm{mL}$ IgE (Abcam, Cambridge, USA) or a combination of $50 \mathrm{ng} / \mathrm{mL}$ rmIL-18 (MBL International, Watertown, USA) and $100 \mathrm{ng} / \mathrm{mL}$ rmIL-33 (Sanquin). For intracellular cytokine staining, cells were stimulated for $11 \mathrm{~h}$, and Golgi-Stop (BD) was added for an additional $4 \mathrm{~h}$.

\section{Statistical analysis}

All statistical analyses were performed in Prism 5.0 (GraphPad Software, San Diego, USA). For comparing 
two experimental conditions, unpaired Student's $t$ test was applied (with Welch's correction if unequal variances were observed). Mann-Whitney $t$ test was applied if no normal distribution was found with D'Agostino \& Pearson omnibus normality test. Median fluorescence intensities were tested by paired Student's $t$ test or Wilcoxon signed rank test (in absence of normal distribution), because all experimental groups were equally distributed at any day for acquisition. Correlations were determined by Spearman's rank correlation. If testing the effect of two variables and their interaction (e.g. culture time and age), two-way ANOVA (TWA) was applied, with Bonferroni post hoc tests (normality verified by Kolmogorov-Smirnov normality test). Values of $p<0.05$ were considered to be statistically significant, and values between $p>0.05$ and $p<0.10$ were considered to be a trend. Significant differences are indicated by asterisks: ${ }^{*}=p<0.05 ;{ }^{* *}=p<0.01 ;{ }^{* * *}=p<0.001$.

\section{Abbreviations}

BAFF: B cell activating factor; BM: bone marrow; BMB: bone marrow-derived basophils; CCL: C-C motif chemokine ligand; GF: germ-free; GM-CSF: granulocytemacrophage colony stimulating factor; Ig: immunoglobulin; IL: interleukin; Lin: lineage; LPS: lipopolysaccharide; SPF: specific pathogen-free; Th: T helper; TLR: Toll-like receptor; TSLP: thymic stromal lymphopoietin; TWA: two-way ANOVA

\section{Acknowledgements}

We would like to thank Theo Borghuis, Mike Peters, and Stefanie Schonfeld for excellent technical assistance.

\section{Funding}

This work was funded by TI Food and Nutrition, a public-private partnership on precompetitive research in food and nutrition. The public partners are responsible for the study design, data collection and analysis, decision to publish, and preparation of the manuscript. The private partners have contributed to the project through regular discussion.

\section{Availability of data and materials}

The datasets used and/or analysed during the current study are available from the corresponding author on reasonable request.

\section{Authors' contributions}

$A B, F F, B M, P V, E K, H S$ conceived the study. $A B, F F, B M$ performed the experiments. $A B$ wrote the manuscript. FF, BM, PV, EK, HS contributed to the revisions of the draft manuscripts. All authors read and approved the final manuscript.

\section{Ethics approval}

The experiments were approved by the Animal Ethical Committee of University Medical Center of Groningen.

\section{Consent for publication}

Not applicable.

\section{Competing interests}

The authors declare that they have no competing interests.

\section{Publisher's Note}

Springer Nature remains neutral with regard to jurisdictional claims in published maps and institutional affiliations.

\section{Author details}

${ }^{1}$ Cell Biology and Immunology Group, Wageningen University, Wageningen, the Netherlands. ${ }^{2}$ Top Institute Food and Nutrition, Wageningen, the Netherlands. ${ }^{3}$ Department of Immunology, Erasmus University Medical
Center, Dr. Molewaterplein 40, 3015 GD Rotterdam, the Netherlands. ${ }^{4}$ Pathology and Medical Biology, University of Groningen, Groningen, the Netherlands. ${ }^{5}$ Department of Immunology, University Medical Center, Utrecht, the Netherlands. ${ }^{6}$ Dermatology/Allergology, University Medical Center, Utrecht, the Netherlands.

Received: 19 July 2018 Accepted: 1 November 2018

Published online: 29 November 2018

\section{References}

1. Luckey T. Introduction to intestinal microecology. Am J Clin Nutr. 1972; 25(12):1292-4

2. Tlaskalová-Hogenová H, Štěpánková R, Kozáková H, Hudcovic T, Vannucci L, Tučková $L$, et al. The role of gut microbiota (commensal bacteria) and the mucosal barrier in the pathogenesis of inflammatory and autoimmune diseases and cancer: contribution of germ-free and gnotobiotic animal models of human diseases. Cell Mol Immunol. 2011;8(2):110-20.

3. Bianconi E, Piovesan A, Facchin F, Beraudi A, Casadei R, Frabetti F, et al. An estimation of the number of cells in the human body. Ann Hum Biol. 2013; 40(6):463-71.

4. Ivanov II, Littman DR. Modulation of immune homeostasis by commensal bacteria. Curr Opin Microbiol. 2011;14(1):106-14.

5. Chu H, Mazmanian SK. Innate immune recognition of the microbiota promotes host-microbial symbiosis. Nat Immunol. 2013;14(7):668-75.

6. Luo Y, Chen G-L, Hannemann N, Ipseiz N, Krönke G, Bäuerle T, et al. Microbiota from obese mice regulate hematopoietic stem cell differentiation by altering the bone niche. Cell Metab. 2015;22(5):886-94.

7. Clarke TB, Davis KM, Lysenko ES, Zhou AY, Yu Y, Weiser JN. Recognition of peptidoglycan from the microbiota by Nod1 enhances systemic innate immunity. Nat Med. 2010;16(2):228-31.

8. Hill DA, Siracusa MC, Abt MC, Kim BS, Kobuley D, Kubo M, et al. Commensal bacteria-derived signals regulate basophil hematopoiesis and allergic inflammation. Nat Med. 2012;18(4):538-46.

9. Dorshkind K, Montecino-Rodriguez E, Signer RAJ. The ageing immune system: is it ever too old to become young again? Nat Rev Immunol. 2009;9(1):57-62.

10. Smith P, Dunne DW, Fallon PG. Defective in vivo induction of functional type 2 cytokine responses in aged mice. Eur J Immunol. 2001;31(5):1495-502.

11. Uciechowski P, Rink L. Basophil, Eosinophil, and Neutrophil Functions in the Elderly. In: Massoud A, Rezaei N. (eds) Immunology of Aging. Berlin: Springer;2014.

12. Biagi E, Nylund L, Candela M, Ostan R, Bucci L, Pini E, et al. Through ageing, and beyond: gut microbiota and inflammatory status in seniors and centenarians. PLoS One. 2010;5(5):e10667.

13. Bieneman AP, Chichester KL, Chen Y-H, Schroeder JT. Toll-like receptor 2 ligands activate human basophils for both lgE-dependent and IgEindependent secretion. J Allergy Clin Immunol. 2005;115(2):295-301.

14. Kamijo S, Nunomura S, Ra C, Kanaguchi Y, Suzuki Y, Ogawa H, et al. Innate basophil IL-4 responses against allergens, endotoxin, and cytokines require the Fc receptor $\gamma$-chain. J Allergy Clin Immunol. 2016;137(5):1613-5. e2.

15. Marone G, Poto S, di Martino L, Condorelli M. Human basophil releasability: I. age-related changes in basophil releasability. J Allergy Clin Immunol. 1986; 77(2):377-83.

16. Schwarzenbach $H$, Nakagawa $T$, Conroy M, Weck A. Skin reactivity, basophil degranulation and IgE levels in ageing. Clin Exp Allergy. 1982;12(5):465-73.

17. Leng $S X$, Xue Q-L, Huang Y, Ferrucci L, Fried LP, Walston JD. Baseline total and specific differential white blood cell counts and 5-year all-cause mortality in community-dwelling older women. Exp Gerontol. 2005;40(12):982-7.

18. Leng SX, Xue Q-L, Tian J, Huang Y, Yeh S-H, Fried LP. Associations of neutrophil and monocyte counts with frailty in community-dwelling disabled older women: results from the Women's health and aging studies I. Exp Gerontol. 2009:44(8):511-6.

19. Shad KF, Aghazadeh Y, Ahmad S, Kress B. Peripheral markers of Alzheimer's disease: surveillance of white blood cells. Synapse. 2013;67(8):541-3.

20. Song C, Vandewoude M, Stevens W, De Clerck L, Van der Planken M, Whelan A, et al. Alterations in immune functions during normal aging and Alzheimer's disease. Psychiatry Res. 1999;85(1):71-80.

21. Van Beek AA, Knol EF, De Vos P, Smelt MJ, Savelkoul HFJ, Van Neerven RJJ. Recent developments in basophil research: do basophils initiate and perpetuate type 2 T-helper cell responses? Int Arch Allergy Immunol. 2013; 160(1):7-17. 
22. Moore ML, Newcomb DC, Parekh W, Van Kaer L, Collins RD, Zhou W, et al. STAT1 negatively regulates lung basophil IL-4 expression induced by respiratory syncytial virus infection. J Immunol. 2009;183(3):2016-26.

23. Chen $\mathrm{K}, \mathrm{Xu}$ W, Wilson M, He B, Miller NW, Bengtén E, et al. Immunoglobulin $D$ enhances immune surveillance by activating antimicrobial, proinflammatory and B cell-stimulating programs in basophils. Nat Immunol. 2009;10(8):889-98.

24. Denzel A, Maus UA, Gomez MR, Moll C, Niedermeier M, Winter C, et al. Basophils enhance immunological memory responses. Nat Immunol. 2008; 9(7):733-42.

25. Charles N, Hardwick D, Daugas E, Illei GG, Rivera J. Basophils and the T helper 2 environment can promote the development of lupus nephritis. Nat Med. 2010;16(6):701-7.

26. Pan Q, Gong L, Xiao H, Feng Y, Li L, Deng Z, et al. Basophil activationdependent autoantibody and interleukin-17 production exacerbate systemic lupus erythematosus. Front Immunol. 2017;8:348.

27. Liang $\mathrm{P}$, Tang $Y$, Fu S, Lv J, Liu B, Feng $\mathrm{M}$, et al. Basophil count, a marker for disease activity in systemic lupus erythematosus. Clin Rheumatol. 2015;34(5): 891-6.

28. Sektioglu IM, Carretero R, Bulbuc N, Bald T, Tuting T, Rudensky AY, et al. Basophils promote tumor rejection via chemotaxis and infiltration of CD8+ T cells. Cancer Res. 2017:77(2):291-302.

29. Siracusa MC, Saenz SA, Hill DA, Kim BS, Headley MB, Doering TA, et al. TSLP promotes interleukin-3-independent basophil haematopoiesis and type 2 inflammation. Nature. 2011;477:229-33.

30. Schneider E, Thieblemont N, De Moraes ML, Dy M. Basophils: new players in the cytokine network. Eur Cytokine Netw. 2010;21(3):142-53.

31. Yoshimoto T, Nakanishi K. Generation and characterization of mouse basophils from bone marrow and purification of basophils from spleen. Curr Protoc Immunol 2012:3.24.1-3..16.

32. Yoshimoto T, Yasuda K, Tanaka H, Nakahira M, Imai Y, Fujimori Y, et al. Basophils contribute to TH2-IgE responses in vivo via IL-4 production and presentation of peptide-MHC class II complexes to CD4+ T cells. Nat Immunol. 2009;10(7):706-12.

33. Kojima T, Obata K, Mukai K, Sato S, Takai T, Minegishi Y, et al. Mast cells and basophils are selectively activated in vitro and in vivo through CD200R3 in an IgE-independent manner. J Immunol. 2007:179(10):7093-100.

34. Gerdes J, Lemke H, Baisch H, Wacker H-H, Schwab U, Stein H. Cell cycle analysis of a cell proliferation-associated human nuclear antigen defined by the monoclonal antibody Ki-67. J Immunol. 1984;133(4):1710-5.

35. Hida S, Yamasaki S, Sakamoto Y, Takamoto M, Obata K, Takai T, et al. Fc receptor $\mathrm{g}$-chain, a constitutive component of the IL-3 receptor, is required for IL-3-induced IL-4 production in basophils. Nat Immunol. 2009;10(2):214-22

36. Shiratori I, Yamaguchi M, Suzukawa M, Yamamoto K, Lanier LL, Saito T, et al. Down-regulation of basophil function by human CD200 and human herpesvirus-8 CD200. J Immunol. 2005;175(7):4441-9.

37. van Beek AA, Hugenholtz F, Meijer B, Sovran B, Perdijk O, Vermeij WP, et al. Tryptophan restriction arrests $B$ cell development and enhances microbial diversity in WT and prematurely aging Ercc1-/D7 mice. J Leukoc Biol. 2016; 101(4):811-21.

38. Mahbub S, Deburghgraeve CR, Kovacs EJ. Advanced age impairs macrophage polarization. J Interf Cytokine Res. 2012;32(1):18-26.

39. Zhang B, Bailey WM, Braun KJ, Gensel JC. Age decreases macrophage IL-10 expression: implications for functional recovery and tissue repair in spinal cord injury. Exp Neurol. 2015;273:83-91.

40. Fransen F, Van Beek A, Borghuis T, El Aidy S, Hugenholtz F, Van der Gaastde Jongh $C$, et al. Aged gut microbiota contributes to systemical inflammaging after transfer to germ-free mice. Front Immunol. 2017;8:1385.

Ready to submit your research? Choose BMC and benefit from:

- fast, convenient online submission

- thorough peer review by experienced researchers in your field

- rapid publication on acceptance

- support for research data, including large and complex data types

- gold Open Access which fosters wider collaboration and increased citations

- maximum visibility for your research: over $100 \mathrm{M}$ website views per year

At BMC, research is always in progress.

Learn more biomedcentral.com/submissions 